Check for updates

Cite this: Mater. Adv., 2020 1, 767

Received 6th April 2020,

Accepted 31st May 2020

DOI: 10.1039/d0ma00172d

rsc.li/materials-advances

\title{
Controlling interface properties for enhanced photocatalytic performance: a case-study of $\mathrm{CuO} / \mathrm{TiO}_{2}$ nanobelts $\dagger$
}

\author{
Huaqiang Zhuang, (D) ${ }^{a b}$ Siying Zhang, ${ }^{a}$ Manru Lin, ${ }^{a}$ Liqin Lin, ${ }^{a}$ Zhenping Cai*c and \\ Wentao Xu*a
}

\begin{abstract}
$\mathrm{TiO}_{2}$ nanobelts with $\mathrm{CuO}$ modification were designed and fabricated via a facile strategy. The photocatalytic degradation of methyl orange (MO) is selected as a model reaction to investigate the photocatalytic performance of all as-prepared $\mathrm{CuO} / \mathrm{TiO}_{2}$ nanobelts under full-spectrum light $(300-2500 \mathrm{~nm})$ irradiation. The optimized mass fraction of $\mathrm{CuO}$ is $0.1 \%$ for $\mathrm{CuO} / \mathrm{TiO}_{2}$ composite nanobelts, namely $\mathrm{CT}-0.1$ sample, which can almost completely degrade $\mathrm{MO}$ pollutant in $50 \mathrm{~min}$. The as-obtained $\mathrm{CuO} / \mathrm{TiO}_{2}$ composites are systematically investigated by a variety of physical and chemical characterizations. Therein, it can be obtained that superoxide radicals $\left(\bullet_{2}{ }^{-}\right.$) and hydroxyl radicals $(\bullet \mathrm{OH})$ are the main active species in this photocatalytic system. The photoelectrochemical measurement clearly demonstrates that the enhanced photocatalytic activity can be attributed to the efficient separation and transfer of photo-generated electron-hole pairs, and lower overpotential for $\mathrm{CuO} / \mathrm{TiO}_{2}$ nanobelts. This work provides a prototype to study the photocatalytic oxidation process, which contributes to the design and construction of highly-efficient composite photocatalysts.
\end{abstract}

\section{Introduction}

Semiconductor-based photocatalysis has been verified to be an effective approach to resolve environmental and energy issues. ${ }^{1-3}$ Among many photocatalysts, $\mathrm{TiO}_{2}$ has been considered to be one of the most promising candidates, owing to its excellent catalytic activity, stability, nontoxicity and low cost. ${ }^{4-6}$ Nevertheless, the wide band gap and low separation and transfer efficiency of photo-generated charge carriers still limit the solar conversion efficiency and large-scale application of $\mathrm{TiO}_{2} \cdot{ }^{7-10}$ As we all know, the photocatalytic process mainly involves the following three steps. ${ }^{11,12}$ The initial step is the generation of photo-excited holeelectron pairs in the photocatalyst under solar light irradiation. Subsequently, the photo-generated electron-hole pairs will be separated and migrate on the surface of the semiconductor photocatalyst. Finally, electrons and holes on the surface will participate in reduction and oxidation reactions to accomplish the solar energy conversion process. Thereinto, the separation of photo-generated electron-hole pairs is one of the important steps

${ }^{a}$ College of Chemical Engineering and Materials Science, Quanzhou Normal University, Quanzhou 362000, P. R. China. E-mail: xuwentao93@aliyun.com

${ }^{b}$ Key Laboratory of Green Energy and Environment Catalysis,

Ningde Normal University, Fujian Province, Ningde, 352100, P. R. China

${ }^{c}$ Department of Chemical Engineering, Norwegian University of Science and

Technology, N-7491, Trondheim, Norway.E-mail: zhenping.cai@ntnu.no

$\dagger$ Electronic supplementary information (ESI) available. See DOI: 10.1039/d0ma00172d for achieving good photocatalytic performance. ${ }^{13-16}$ Therefore, a large number of efforts have been devoted to enhancing the separation efficiency of photo-generated electron-hole pairs to improve the photocatalytic activity.

A variety of strategies, such as metal or nonmetal doping, semiconductor compositing and cocatalyst modifying, have been developed to improve the separation and transfer efficiency of photo-generated charge carriers. ${ }^{17-20} \mathrm{Jing}$ et $a .^{21}$ reported that BiOCl was modified by RGO and phosphate groups to improve the photogenerated charge separation and photochemical stability. Similarly, some noble metals are normally regarded as active sites to enhance the separation and transfer efficiency of photogenerated electron-hole pairs. The ultrafast charge separation and long-lived charge separated state of $\mathrm{CdS}$ nanorods were directly demonstrated by the introduction of Pt nanoparticles. ${ }^{22}$ In addition, some transition metal oxides, such as $\mathrm{CuO}$, $\mathrm{NiO}$ and $\mathrm{Co}_{3} \mathrm{O}_{4}$, can also act as cocatalysts to improve photocatalytic performance. For example, Reddy et $a .^{23}$ reported that $\mathrm{CuO}$ quantum dots as cocatalysts could boost the photocatalytic hydrogen production of $\mathrm{TiO}_{2}$. The $\mathrm{CuO}$ nanoparticles were introduced on flower-like $\mathrm{ZnO}$ to construct a $0 \mathrm{D}-3 \mathrm{D} \mathrm{CuO} / \mathrm{ZnO}$ heterojunction, which enhanced the separation efficiency of the photogenerated electron-hole pairs resulting in enhanced photocatalytic performance. ${ }^{24}$ Some previous reports ${ }^{25-28}$ also demonstrate that $\mathrm{NiO}$ and $\mathrm{Co}_{3} \mathrm{O}_{4}$ can act as cocatalysts to improve the photocatalytic activity. These research studies suggest that transition 
metal oxides have considerable potential to replace noble metals and can be applied in the photocatalytic field.

$\mathrm{CuO}$ is a promising candidate to act as a cocatalyst, attributed to its low cost, narrow band gap and nontoxicity. ${ }^{29-31}$ Furthermore, $\mathrm{CuO}$ has the ability to enhance the utilization efficiency of solar energy and accelerate the separation of photo-excited charge carriers after surface modification on $\mathrm{TiO}_{2}$. Wang et al. ${ }^{32}$ reported that $\mathrm{CuO}$ quantum dots incorporated into $\mathrm{TiO}_{2}$ nanosheets could obviously improve photocatalytic water splitting performance. $\mathrm{Lu}$ et al. directly ${ }^{33}$ revealed the role of $\mathrm{CuO}$ in the plasmonic photocatalysis of $\mathrm{Ag} / \mathrm{AgCl} / \mathrm{TiO}_{2}$, which could enhance the photocatalytic activity for degradation of methyl orange and phenol. It can be seen that the electronic band structure of $\mathrm{CuO}$ is very well matched with that of $\mathrm{TiO}_{2}$, which is beneficial for the separation and transfer of photo-generated electron-hole pairs. Although lots of studies focus on the $\mathrm{CuO} / \mathrm{TiO}_{2}$ photocatalyst, the enhanced nature of $\mathrm{CuO}$ nanoparticles incorporated on $\mathrm{TiO}_{2}$ nanobelts is still lacking in systematic research.

In this work, we show a facile method to prepare $\mathrm{CuO} / \mathrm{TiO}_{2}$ nanobelts for the degradation of methyl orange (MO). The composition and structure of $\mathrm{CuO} / \mathrm{TiO}_{2}$ nanobelts with different $\mathrm{CuO}$ content were systematically characterized by XRD, SEM and DRS measurements. The CT-0.1 sample displays the best photocatalytic performance compared to the others for the degradation of methyl orange (MO). Furthermore, the active species trapping experiments demonstrate that superoxide radicals $\left({ }^{\bullet} \mathrm{O}_{2}{ }^{-}\right)$and hydroxyl radicals $\left({ }^{\bullet} \mathrm{OH}\right)$ are the main active species in this photocatalytic system. The enhanced photocatalytic activity can be attributed to the efficient separation and transfer of photogenerated electron-hole pairs. In addition, the as-prepared CT-0.1 sample shows a lower overpotential, which is beneficial for photocatalytic oxidation processes.

\section{Experimental}

\subsection{Catalyst preparation}

$\mathrm{TiO}_{2}$ nanobelts. The $\mathrm{TiO}_{2}$ nanobelts were synthesized via a typical hydrothermal method. In a typical preparation process, $0.4 \mathrm{~g}$ of $\mathrm{TiO}_{2}$ power (P25) was added to $72 \mathrm{~mL}$ of $10 \mathrm{M} \mathrm{NaOH}$ aqueous solution under continuous ultrasound treatment for $40 \mathrm{~min}$. Then, the mixed solution was transferred to a $100 \mathrm{~mL}$ Teflon-lined stainless steel autoclave and heated at $200{ }^{\circ} \mathrm{C}$ for $24 \mathrm{~h}$. After the completion of the reaction, the as-prepared samples were washed with deionized water several times. Subsequently, the as-obtained samples were immersed in $0.1 \mathrm{~mol} \mathrm{~L}^{-1} \mathrm{HCl}$ aqueous solution for 13 hours. After that, the wet products were washed until the solution $\mathrm{pH}$ value reached 7 , and then the $\mathrm{H}_{2} \mathrm{Ti}_{3} \mathrm{O}_{7}$ nanobelts were dried at $60{ }^{\circ} \mathrm{C}$ for 24 hours. Finally, the $\mathrm{TiO}_{2}$ nanobelts were obtained by post-calcination treatment for $3 \mathrm{~h}$ at $450{ }^{\circ} \mathrm{C}$.

$\mathrm{CuO} / \mathrm{TiO}_{2}$ nanobelts. The $\mathrm{CuO}$ nanoparticles were incorporated on $\mathrm{TiO}_{2}$ nanobelts using a facile wetness impregnation method. A certain amount of $\mathrm{Cu}\left(\mathrm{NO}_{3}\right)_{2}$ aqueous solution $\left(10 \mathrm{mg} \mathrm{mL}^{-1}\right)$ was added to $0.4 \mathrm{~g}$ of $\mathrm{H}_{2} \mathrm{Ti}_{3} \mathrm{O}_{7}$ nanobelts, and then ultrasonically treated for $30 \mathrm{~min}$. Subsequently, the mixed solution was dried in an oven at $110{ }^{\circ} \mathrm{C}$ for 12 hours. After that, the mixed composites with different $\mathrm{Cu}$ content were further calcined for $3 \mathrm{~h}$ at $450{ }^{\circ} \mathrm{C}$, and the $\mathrm{CuO} / \mathrm{TiO}_{2}$ nanobelts were obtained. The mass contents of $\mathrm{CuO}$ in the $\mathrm{CuO} / \mathrm{TiO}_{2}$ composite materials were adjusted to be $0.1 \%, 0.25 \%, 0.5 \%, 1 \%$, and $3 \%$, which were labeled as CT-0.1, CT-0.25, CT-0.5, CT-1 and CT-3, respectively.

\subsection{Characterization of samples}

XRD plots were measured on a Bruker D8 Advance X-ray diffractometer with $\mathrm{Cu} \mathrm{K} \alpha$ radiation $(\lambda=1.5406 \AA)$. UV-vis DRS spectra were recorded on a Varian Cary 500 Scan UV-vis-NIR spectrometer with $\mathrm{BaSO}_{4}$ as the reference. The Hitachi New Generation SU8010 field emission scanning electron microscope was used to obtain SEM images. The Brunauer-Emmett-Teller (BET) specific surface areas were determined by $\mathrm{N}_{2}$ adsorption at $77 \mathrm{~K}$ on a Micromeritics ASAP 2020. XPS spectra were recorded on a VGESCALAB 250 XPS system with a monochromatized Al K $\alpha$ X-ray source $(15 \mathrm{kV} 200 \mathrm{~W} 500 \mu \mathrm{m}$ pass energy $=20 \mathrm{eV})$. All binding energies were referenced to the $\mathrm{C} 1 \mathrm{~s}$ peak at $284.6 \mathrm{eV}$ of surface adventitious carbon. HRTEM images were obtained on the JEM $2100 \mathrm{~F}$ instrument at an accelerating voltage of $200 \mathrm{kV}$. Photocurrent was measured using the conventional three-electrode electrochemical cell with a working electrode, a platinum foil counter electrode and an $\mathrm{Ag} / \mathrm{AgCl}$ electrode as the reference electrode. The working electrode was fabricated on the FTO glass: $10 \mathrm{mg}$ of the sample was mixed with $0.5 \mathrm{~mL}$ ethanol under continuous stirring for $3 \mathrm{~h}$ to obtain the slurry. Then, $40 \mu \mathrm{L}$ of the slurry was spread onto FTO glass the sides of which had previously been protected by Scotch tape, and the electrode was dried at room temperature for $24 \mathrm{~h}$. In the experiment, the three electrodes were immersed in a sodium sulfate electrolyte solution $(0.5 \mathrm{M})$ and the working electrode was irradiated with full-spectrum light. Light/dark short circuit photocurrent response and electrochemical impedance spectroscopy (EIS) experiments were performed using an electrochemical workstation (CHI 660E).

\subsection{Photocatalytic activity measurement}

The photocatalytic performance of the as-prepared samples was evaluated by the degradation of MO in aqueous solution. A 300 W PLS-SXE300 Xe lamp with full-spectrum light (300$2500 \mathrm{~nm}$ ) was used as the light source. Typically, $80 \mathrm{mg}$ of the photocatalyst was added to $80 \mathrm{~mL}$ of $10 \mathrm{mg} \mathrm{L}^{-1} \mathrm{MO}$ aqueous solution in a container. Prior to irradiation, the suspensions were magnetically stirred in the dark for $60 \mathrm{~min}$ to ensure the establishment of an adsorption/desorption equilibrium between the photocatalyst and MO. At given irradiation time intervals, $4 \mathrm{~mL}$ of suspension was collected and centrifuged to remove the photocatalyst particles, and then the residual MO solution was analyzed by monitoring variations at the wavelength of maximal absorption in the UV-vis spectra.

\subsection{Active species trapping experiments}

In order to probe the active species generated in the photocatalytic reaction process, isopropanol (IPA), $\mathrm{Na}_{2} \mathrm{C}_{2} \mathrm{O}_{4}$ and $p$-benzoquinone (BQ) as the scavengers of hydroxyl radicals $\left({ }^{\bullet} \mathrm{OH}\right)$, holes $\left(\mathrm{h}^{+}\right)$and superoxide radicals $\left({ }^{\bullet} \mathrm{O}_{2}{ }^{-}\right)$were, respectively, 
added to the MO solution to study the influence of different active species. The concentrations of IPA, $\mathrm{Na}_{2} \mathrm{C}_{2} \mathrm{O}_{4}$ and BQ were $1 \mathrm{mmol} \mathrm{L}^{-1}, 1 \mathrm{mmol} \mathrm{L}^{-1}$ and $1 \mathrm{mmol} \mathrm{L}^{-1}$, respectively. The photocatalytic degradation reaction was similar to the above test condition except for adding scavengers in the MO solution.

\section{Results and discussion}

The as-prepared samples were investigated by scanning electron microscopy (SEM) so as to characterize their morphologies before and after $\mathrm{CuO}$ surface-modification of $\mathrm{TiO}_{2}$ nanobelts. Fig. 1 shows the SEM images of the TiO ${ }_{2}$, CT-0.1, CT- 1 and CT-3 samples. For the pure $\mathrm{TiO}_{2}$ samples, the nanobelts are $30-60 \mathrm{~nm}$ in thickness, $100-300 \mathrm{~nm}$ in width, and the lengths range up to a few micrometers. The CT-0.1, CT- 1 and CT-3 samples also display similar morphologies, which can be attributed to the low $\mathrm{CuO}$ loading amount. In order to verify the existence and particle size distribution of CuO, the CT-3 sample was further characterized by transmission electron microscopy (TEM). Fig. 2(a) and (b) show the TEM images of the CT-3 sample. It can be seen that the surface of $\mathrm{TiO}_{2}$ contains some small particles, and they are

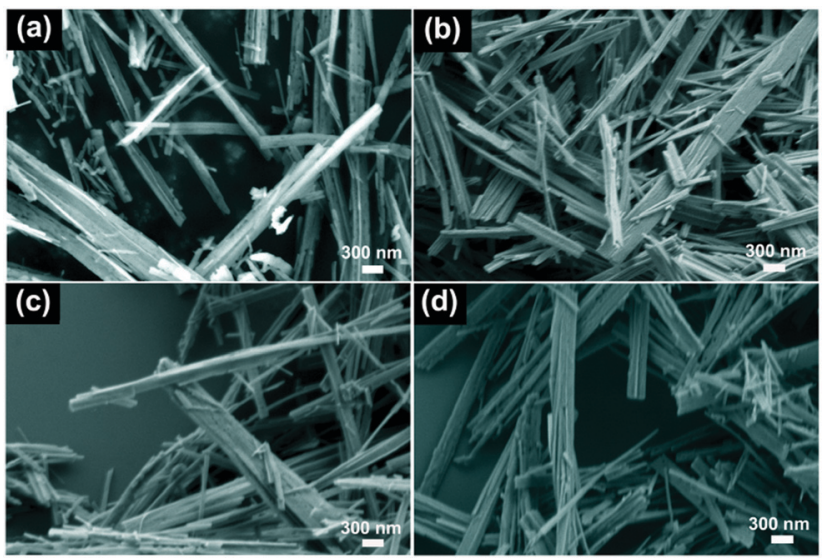

Fig. 1 SEM images of (a) $\mathrm{TiO}_{2}$, (b) CT-0.1, (c) CT-1 and (d) CT-3 samples.

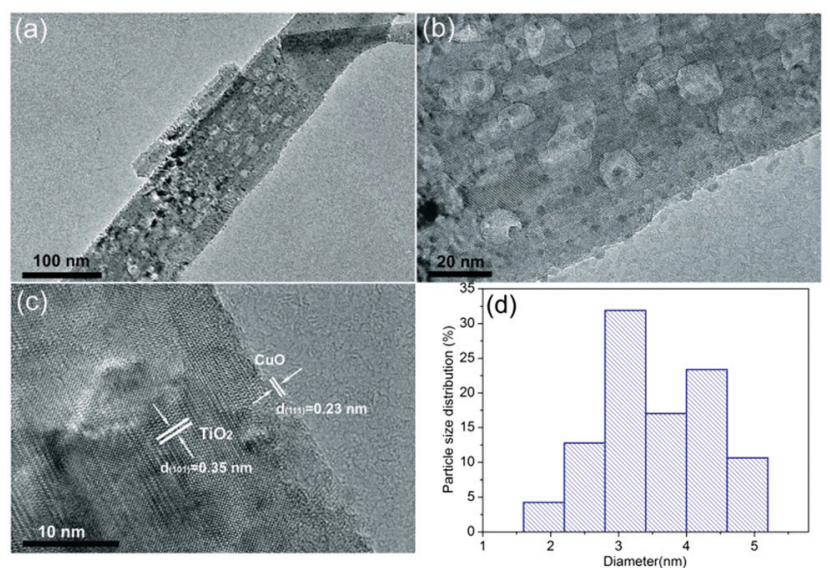

Fig. 2 ( $a$ and $b$ ) TEM images of the CT-3 sample. (c) HRTEM image of the CT-3 sample. (d) Particle size distribution of $\mathrm{CuO}$ on the surface of $\mathrm{TiO}_{2}$ nanobelts. uniformly dispersed on the surface. These particles are $\mathrm{CuO}$ nanoparticles, which can be verified from Fig. 2(c). The distinct lattice fringes with a distance of about $0.35 \mathrm{~nm}$ can be observed, which is assigned to the (101) crystal plane of anatase $\mathrm{TiO}_{2} \cdot{ }^{4}$ In addition, the lattice fringes of $d$-spacings of about $0.23 \mathrm{~nm}$ can be obtained, which is consistent with the (111) crystal plane of CuO. ${ }^{24}$ Fig. 2(d) shows the particle size distribution of $\mathrm{CuO}$ on the $\mathrm{TiO}_{2}$ nanobelts. It clearly shows that most of the $\mathrm{CuO}$ particles are less than 10 nanometers. These results suggest that $\mathrm{CuO}$ particles can be uniformly loaded on the surface of $\mathrm{TiO}_{2}$ nanobelts via this facile strategy.

In addition, all of the as-prepared samples were further characterized by X-ray diffraction measurements (XRD), as presented in Fig. 3. Obviously, the nude $\mathrm{TiO}_{2}$ nanobelts display the characteristic diffraction peaks of $\mathrm{TiO}_{2} \cdot{ }^{34}$ Similarly, the $\mathrm{CuO} /$ $\mathrm{TiO}_{2}$ nanobelts with different $\mathrm{CuO}$ contents also exhibit the characteristic diffraction peaks of $\mathrm{TiO}_{2}$. However, new diffraction peaks appear at $35.5^{\circ}$ and $38.7^{\circ}$, which are assigned to the (002) and (111) crystal planes of cubic CuO (JCPDS 45-0937), ${ }^{35}$ as shown in Fig. 2(b). The above results suggest that the $\mathrm{CuO} / \mathrm{TiO}_{2}$ nanobelts with different $\mathrm{CuO}$ contents are successfully prepared. To investigate the influence of the specific surface area after the introduction of $\mathrm{CuO}, \mathrm{TiO}_{2}$ and CT-0.1 samples are further characterized by $\mathrm{N}_{2}$ adsorption-desorption measurements, as shown in Table S1 (ESI $\dagger$ ). Obviously, the measured specific surface areas are 54.4 and $59.3 \mathrm{~m}^{2} \mathrm{~g}^{-1}$ for $\mathrm{TiO}_{2}$ and CT-0.1 sample, respectively. It can be concluded that the introduction of $\mathrm{CuO}$ doesn't obviously enhance the specific surface area of $\mathrm{TiO}_{2}$.

XPS spectroscopy was carried out to investigate the chemical status of $\mathrm{Ti}, \mathrm{O}$ and $\mathrm{Cu}$ elements in $\mathrm{CuO} / \mathrm{TiO}_{2}$ nanobelts, as displayed in Fig. 4. Fig. 4(a) presents the XPS survey spectra of the CT-3 sample, indicating that the CT-3 sample contains Ti, O and $\mathrm{Cu}$ elements. The high-resolution XPS spectra of Ti $2 \mathrm{p}$ and $\mathrm{O}$ 1s are shown in Fig. 4(b) and (c), respectively. It can be concluded that the two peaks at $458.6 \mathrm{eV}$ and $464.3 \mathrm{eV}$ are assigned to $\mathrm{Ti} 2 \mathrm{p}_{3 / 2}$ and $\mathrm{Ti} 2 \mathrm{p}_{1 / 2}$ of $\mathrm{Ti}^{4+}$ in $\mathrm{TiO}_{2}$, respectively. Similarly, the binding energy of the $\mathrm{O} 1 \mathrm{~s}$ peak at $529.9 \mathrm{eV}$ can be assigned to lattice oxygen, and the other peak at $530.6 \mathrm{eV}$ is identified with surface hydroxyls in $\mathrm{CuO} / \mathrm{TiO}_{2} \cdot{ }^{36}$ Importantly, there are two peaks located at approximately $932.5 \mathrm{eV}$ and $952.1 \mathrm{eV}$, corresponding to $\mathrm{Cu} 2 \mathrm{p}_{3 / 2}$ and $\mathrm{Cu} 2 \mathrm{p}_{1 / 2}$, respectively. In addition, the two satellite peaks for $\mathrm{Cu}^{2+}$ can also be clearly
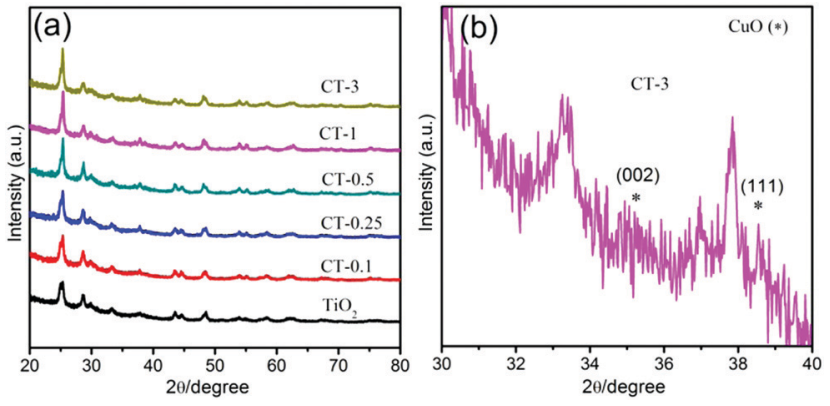

Fig. 3 (a) XRD patterns of $\mathrm{TiO}_{2}$ and $\mathrm{CuO} / \mathrm{TiO}_{2}$ nanobelts. (b) $\mathrm{A}$ larger version of the CT-3 sample. 

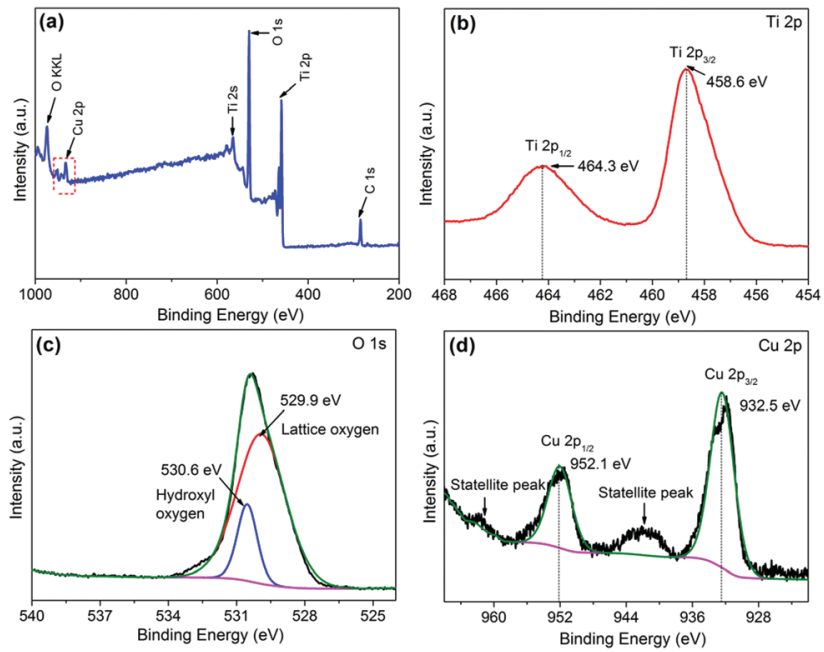

Fig. 4 (a) Typical XPS survey spectra of the CT-3 sample. The high resolution XPS spectra of Ti $2 p, O 1 s$ and $\mathrm{Cu} 2 p$ (b, $c$ and $d$, respectively) for the CT-3 sample.

observed in Fig. 4(d). ${ }^{37,38}$ These results further confirm the existence of $\mathrm{CuO}$ in the CT-3 sample.

The optical absorption properties of $\mathrm{TiO}_{2}$ and $\mathrm{CuO} / \mathrm{TiO}_{2}$ nanobelts were characterized in detail using ultraviolet-visible diffuse reflectance absorption spectra (DRS), as shown in Fig. 5. It can be clearly observed that the absorption band of $\mathrm{TiO}_{2}$ nanosheets is below $400 \mathrm{~nm}$ assigned to the intrinsic bandgap absorption of $\mathrm{TiO}_{2} \cdot{ }^{5}$ As expected, the photo-absorption efficiency of $\mathrm{CuO} / \mathrm{TiO}_{2}$ nanobelts is slightly enhanced in the visible light region after coupling with $\mathrm{CuO}$ nanoparticles, which is attributed to the narrower bandgap of $\mathrm{CuO}(\mathrm{ca} \cdot 1.7 \mathrm{eV}) .{ }^{39}$ Obviously, the visible light absorption shows a considerable improvement with the increasing $\mathrm{CuO}$ content in $\mathrm{CuO} / \mathrm{TiO}_{2}$ nanobelts. The enhanced optical adsorption of $\mathrm{CuO} / \mathrm{TiO}_{2}$ nanobelts is mainly ascribed to the $\mathrm{d}-\mathrm{d}$ transition of $\mathrm{Cu}^{2+} \cdot{ }^{40}$ It can be concluded that the special phenomenon is another piece of solid evidence to verify the existence of $\mathrm{CuO}$ species in the $\mathrm{CuO} / \mathrm{TiO}_{2}$ nanobelts.

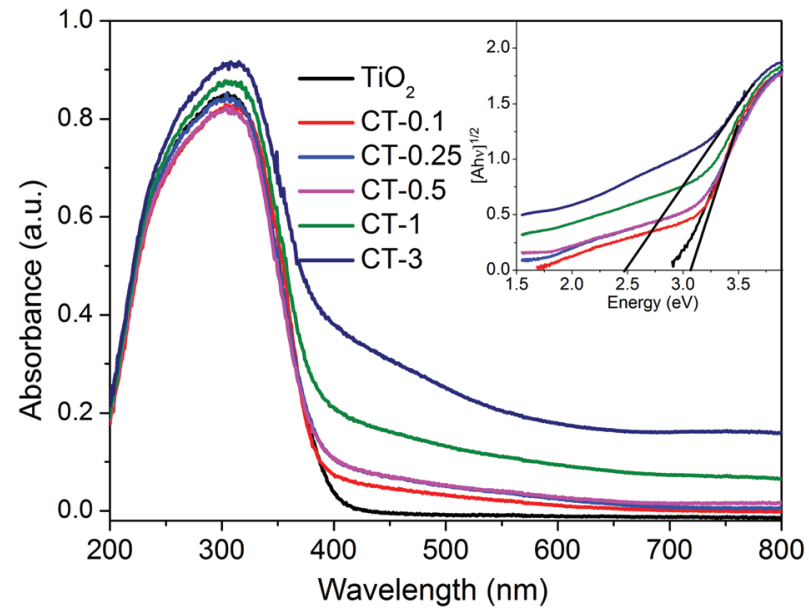

Fig. 5 UV-vis DRS spectra of $\mathrm{TiO}_{2}$ and $\mathrm{CuO} / \mathrm{TiO}_{2}$ nanobelts. The inset shows the plots of $[F(R) h \nu]^{1 / 2}$ versus photon energy $(h \nu)$.

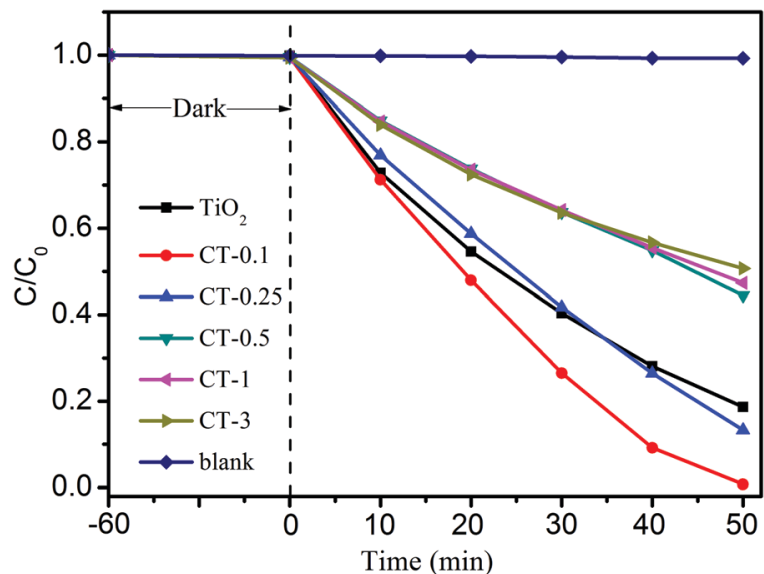

Fig. 6 Photocatalytic activity of $\mathrm{MO}$ degradation for $\mathrm{TiO}_{2}$ and $\mathrm{CuO} / \mathrm{TiO}_{2}$ nanobelts under full-spectrum light irradiation.

The photocatalytic performance of $\mathrm{TiO}_{2}$ and $\mathrm{CuO} / \mathrm{TiO}_{2}$ samples for the degradation of MO was investigated under full-spectrum light irradiation, as shown in Fig. 6. Obviously, the blank experiment shows a negligible photocatalytic activity, indicating that only MO solution can't be degraded without a photocatalyst under full-spectrum light irradiation. After coupling with $\mathrm{CuO}$ nanoparticles, the $\mathrm{CuO} / \mathrm{TiO}_{2}$ nanobelts exhibit an evident improvement with the increase of $\mathrm{CuO}$ content. The CT-0.1 sample displays the best photocatalytic performance compared with that of $\mathrm{TiO}_{2}$ and the other $\mathrm{CuO} / \mathrm{TiO}_{2}$ nanobelts, and its degradation percent of $\mathrm{MO}$ reaches up to $99.2 \%$ in $50 \mathrm{~min}$. Generally, the kinetics of the degradation reaction is investigated by applying the LangmuirHinshelwood (L-H) model. ${ }^{41}$ The apparent reaction rate constants $(k)$ are displayed in Table $\mathrm{S} 1$ (ESI $\dagger)$. Therein, the reaction rate constants for different samples were presented in the following order: CT-0.1 > CT-0.25 > $\mathrm{TiO}_{2}>$ CT-0.5 > CT- $1>$ CT- 3 . It can be concluded that introducing a certain amount of $\mathrm{CuO}$ nanoparticles is beneficial for the photocatalytic oxidation process. However, the photocatalytic activity of $\mathrm{CuO} / \mathrm{TiO}_{2}$ nanobelts shows a significant decrease, when the $\mathrm{CuO}$ content is more than $0.25 \%$. The reduced photocatalytic activity may be attributed to the excessive amount of $\mathrm{CuO}$ nanoparticles that will act as recombination centers for photo-generated electron-hole pairs. Furthermore, the stability of CT-0.1 sample was fully investigated through a cycling experiment under full-spectrum light irradiation, as indicated in Fig. S1 (ESI $\dagger$ ). After four recycling runs, the CT-0.1 sample can still retain degradation activity, and no apparent loss can be found. This clearly indicates that the $\mathrm{CuO} / \mathrm{TiO}_{2}$ nanobelts have excellent stability.

In order to explore the possible reaction mechanism, the active species trapping experiments for the CT-0.1 sample were further investigated by adding some scavengers during the photocatalytic reaction process, as shown in Fig. 7. It can be easily seen that no obvious inhibiting action can be found using $1 \mathrm{mmol} \mathrm{L}^{-1} \mathrm{Na}_{2} \mathrm{C}_{2} \mathrm{O}_{4}$ as the scavenger to quench the $\mathrm{h}^{+},{ }^{42}$ whereas the photocatalytic performance of the CT-0.1 sample has been weakening to some extent. Therein, it can be obtained that $\mathrm{h}^{+}$is not the major active species in the system, but it can 


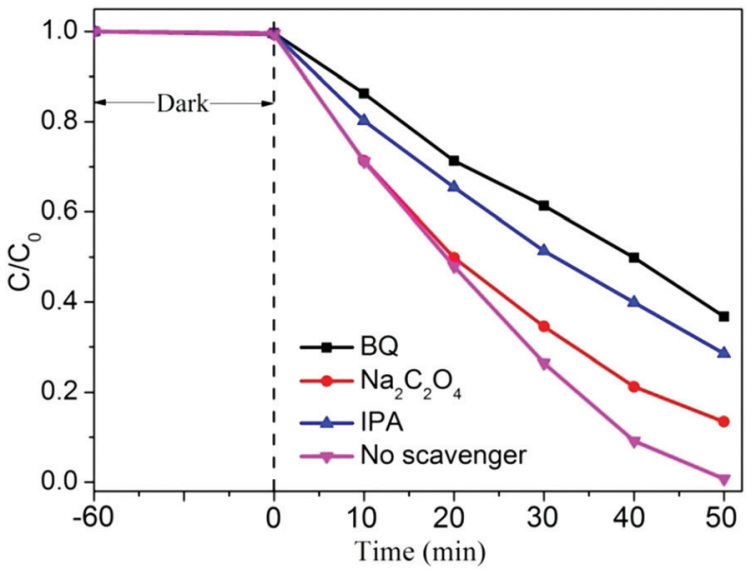

Fig. 7 Active species trapping experiment of the CT-0.1 sample in the photocatalytic reaction process.

influence the photocatalytic activity of the CT-0.1 sample. Interestingly, when isopropanol (IPA) or $p$-benzoquinone (BQ) was added to the MO solution during the photocatalytic reaction process, ${ }^{43}$ the photocatalytic activity of the CT-0.1 sample was evidently inhibited. This suggests that both superoxide radicals $\left({ }^{\circ} \mathrm{O}_{2}^{-}\right)$and hydroxyl radicals $\left({ }^{\circ} \mathrm{OH}\right)$ are main active species, and play a decisive role during the photocatalytic degradation of MO.

The photoelectrochemical (PEC) measurement was investigated to fully elucidate the role of the $\mathrm{CuO}$ cocatalyst under full-spectrum light irradiation. The photocurrent response can directly reflect the generation, separation and transfer of photo-generated electronhole pairs, which is an effective approach to monitor the interface reaction of the photocatalyst. ${ }^{43,44}$ Fig. 8 shows the periodic on/off transient photocurrent response of $\mathrm{TiO}_{2}$ and $\mathrm{CuO} / \mathrm{TiO}_{2}$ samples. Evidently, the CT-0.1 sample displays a higher photocurrent density than that of the nude $\mathrm{TiO}_{2}$ and the other $\mathrm{CuO} / \mathrm{TiO}_{2}$ nanobelts, suggesting that the CT-0.1 sample possesses a much higher separation and transfer efficiency and longer lifetime of the photo-generated charge carriers. The photocurrent density follows the order of CT- $0.1>$ CT- $0.25>\mathrm{TiO}_{2}>$ CT- $0.5>$ CT- $1>$ CT- 3 .

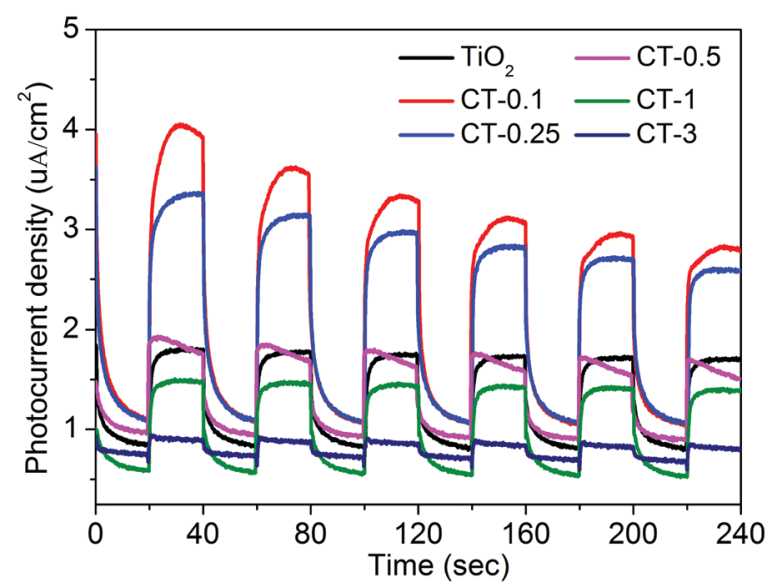

Fig. 8 Transient photocurrent responses of $\mathrm{TiO}_{2}$ and $\mathrm{CuO} / \mathrm{TiO}_{2}$ nanobelts at $0 \mathrm{~V} v \mathrm{~s}$. $\mathrm{Ag} / \mathrm{AgCl}$ under full-spectrum light irradiation.

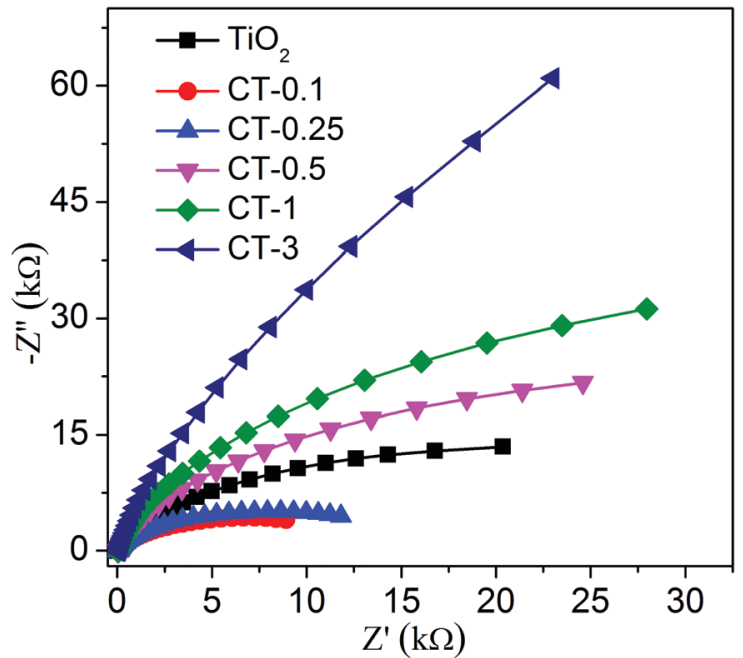

Fig. 9 Electrochemical impedance spectroscopy (EIS) was performed using $\mathrm{TiO}_{2}$ and $\mathrm{CuO} / \mathrm{TiO}_{2}$ nanobelts under full-spectrum light irradiation.

In order to further illustrate the corresponding charge transfer mechanism, electrochemical impedance spectroscopy (EIS) was carried out, as presented in Fig. 9. It is a powerful method to obtain more detailed information about the charge transport, in which the arc radius can reflect the resistance for charge transfer at the electrode/electrolyte interface. ${ }^{45}$ Apparently, the CT-0.1 sample shows a smaller arc radius than that of $\mathrm{TiO}_{2}$ and the other $\mathrm{CuO} / \mathrm{TiO}_{2}$ nanobelts, suggesting enhanced charge carrier separation and increased charge carrier mobility in line with the photocurrent measurements. Herein, the results of the photoelectrochemical measurements demonstrate that a small amount of $\mathrm{CuO}$ has an outstanding ability to enhance the separation and transfer of photo-generated electron-hole pairs for the composite interface. In addition, the applied potential bias-dependent photocurrent density of the $\mathrm{TiO}_{2}, \mathrm{CT}-0.1$ and CT-3 samples was implemented under full-spectrum light irradiation or dark conditions, as shown in Fig. S2 (ESI†). It can be concluded that the CT- 0.1 sample displays a smaller overpotential for the oxygen production reaction in comparison with the $\mathrm{TiO}_{2}$ and CT-3 samples, indicating that the lower overpotential of CT-0.1 sample may be more beneficial for the photocatalytic oxidation process. As mentioned above, it can be concluded that the CT-0.1 sample having excellent photocatalytic performance is mainly ascribed to the efficient separation and transfer of photogenerated electron-hole pairs, and low overpotential for the photocatalytic oxidation process.

In consideration of the above results, the possible photocatalytic reaction mechanism is presented in Fig. 10. Because the work function of $\mathrm{TiO}_{2}(4.7 \mathrm{eV})$ is smaller than that of $\mathrm{CuO}$ $(5.3 \mathrm{eV}),{ }^{40}$ a built-in electric field will be formed between $\mathrm{TiO}_{2}$ and $\mathrm{CuO}$, and the electric fields point out from $\mathrm{CuO}$ to $\mathrm{TiO}_{2}$ before light irradiation. ${ }^{46}$ When the $\mathrm{TiO}_{2}$ nanobelts were irradiated by full-spectrum light, the electrons in the conduction band of $\mathrm{TiO}_{2}$ will be transferred to the conduction band of $\mathrm{CuO}$ due to the existence of the built-in electric field. Therein, the electrons in the conduction band of $\mathrm{CuO}$ will reduce $\mathrm{O}_{2}$ to superoxide radicals $\left({ }^{\circ} \mathrm{O}_{2}^{-}\right)$, and the holes in the valence band of $\mathrm{TiO}_{2}$ will oxidize $\mathrm{H}_{2} \mathrm{O}$ 


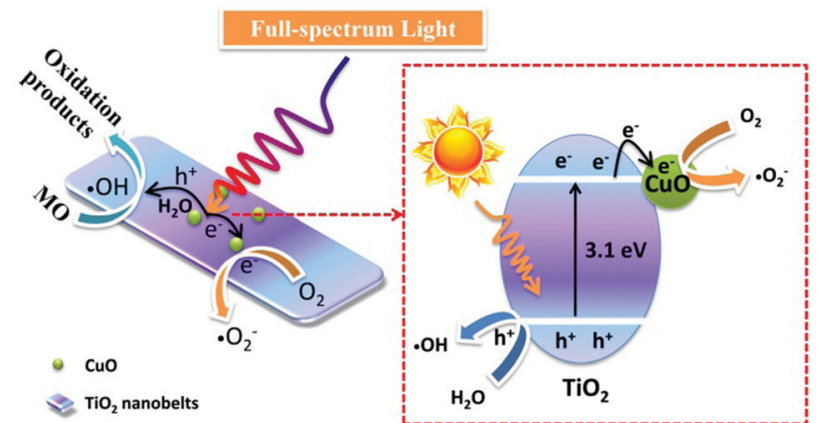

Fig. 10 Proposed mechanism for the enhanced photocatalytic activity for $\mathrm{CuO} / \mathrm{TiO}_{2}$ nanobelts.

into hydroxyl radicals $\left({ }^{\bullet} \mathrm{OH}\right)$ to participate in the photocatalytic degradation of MO.

\section{Conclusions}

In this work, $\mathrm{CuO} / \mathrm{TiO}_{2}$ nanobelts were designed and fabricated to study the photocatalytic oxidation process via a facile strategy. Therein, the CT-0.1 sample displays the best photocatalytic performance for the degradation of MO compared to that of nude $\mathrm{TiO}_{2}$ and the other $\mathrm{CuO} / \mathrm{TiO}_{2}$ nanobelts. The enhanced photocatalytic activity is mainly attributed to the introduction of proper CuO nanoparticles. It can obviously enhance the optical absorption efficiency of $\mathrm{TiO}_{2}$ nanobelts. According to the active species trapping experiments, it can be concluded that superoxide radicals $\left({ }^{\bullet} \mathrm{O}_{2}{ }^{-}\right)$and hydroxyl radicals $\left({ }^{\bullet} \mathrm{OH}\right)$ are the main active species in this photocatalytic system. In addition, the photoelectrochemical measurement demonstrates that the efficient separation and transfer of photo-generated electron-hole pairs and low overpotential of the $\mathrm{CuO} / \mathrm{TiO}_{2}$ nanobelts are beneficial for the photocatalytic oxidation process.

\section{Conflicts of interest}

There are no conflicts to declare.

\section{Acknowledgements}

This work was supported by the Science and Technology Project of Education Department of Fujian Province (JAT170489), the Quanzhou Science and Technology Project (2017Z031), and the Open Project Program of Provincial Key Laboratory of Green Energy and Environment Catalysis (Grant No. FJ-GEEC201907), Ningde Normal University.

\section{Notes and references}

1 L. Wang, Z. Xiao, Y. Liu, S. Cao, Z. Ma and L. Piao, Sci. China Mater., 2020, 63, 758-768.

2 H. Zhuang, W. Xu, L. Lin, M. Huang, M. Xu, S. Chen and Z. Cai, J. Mater. Sci. Technol., 2019, 35, 2312-2318.
3 Y. Wang, R. Shi, J. Lin and Y. Zhu, Energy Environ. Sci., 2011, 4, 2922-2929.

4 H. Zhuang, W. Chen, W. Xu and X. Liu, Int. J. Energy Res., 2020, 44, 3224-3230.

5 H. Zhuang, Y. Zhang, Z. Chu, J. Long, X. An, H. Zhang, H. Lin, Z. Zhang and X. Wang, Phys. Chem. Chem. Phys., 2016, 18, 9636-9644.

6 S. Wu, H. Hu, Y. Lin, J. Zhang and Y. H. Hu, Chem. Eng. J., 2020, 382, 122842.

7 C. Xu, F. Yang, B. Deng, Y. Zhuang, D. Li, B. Liu, W. Yang and Y. Li, J. Catal., 2020, 383, 1-12.

8 K. Maver, I. Arčon, M. Fanetti, S. Emin, M. Valant and U. L. Štangar, Catal. Today, 2020, DOI: 10.1016/j.cattod. 2020.01.045.

9 J. Xue, F. Song, X. Dong, X.-W. Yin, Y. Liu, J.-M. Wu, C. Wang, X.-L. Wang and Y.-Z. Wang, ACS Sustainable Chem. Eng., 2019, 7, 1973-1979.

10 F. Yang, M. Liu, X. Chen, Z. Xu and H. Zhao, Sol. RRL, 2018, 2, 1800215.

11 J. Yang, D. Wang, H. Han and C. Li, Acc. Chem. Res., 2013, 46, 1900-1909.

12 P. Zhang, T. Wang, X. Chang and J. Gong, Acc. Chem. Res., 2016, 49, 911-921.

13 Z.-K. Tang, W.-J. Yin, Z. Le, B. Wen, D.-Y. Zhang, L.-M. Liu and W.-M. Lau, Sci. Rep., 2016, 6, 32764.

14 J. Hu, P. Zhang, W. An, L. Liu, Y. Liang and W. Cui, Appl. Catal., B, 2019, 245, 130-142.

15 F. M. Pesci, G. Wang, D. R. Klug, Y. Li and A. J. Cowan, J. Phys. Chem. C, 2013, 117, 25837-25844.

16 S. Li, Z. Zhao, Y. Huang, J. Di, Y. Jia and H. Zheng, J. Mater. Chem. A, 2015, 3, 5467-5473.

17 M. Wang, J. Han, Y. Hu and R. Guo, $R S C A d v ., 2017$, 7, 15513-15520.

18 L. Hammarström, Acc. Chem. Res., 2015, 48, 840-850.

19 J. F. Guayaquil-Sosa, B. Serrano-Rosales, P. J. Valadés-Pelayo and H. de Lasa, Appl. Catal., B, 2017, 211, 337-348.

20 L. Guo, C. Zhong, J. Cao, Y. Hao, M. Lei, K. Bi, Q. Sun and Z. L. Wang, Nano Energy, 2019, 62, 513-520.

21 Z. Li, Y. Qu, K. Hu, M. Humayun, S. Chen and L. Jing, Appl. Catal., B, 2017, 203, 355-362.

22 K. Wu, H. Zhu, Z. Liu, W. Rodríguez-Córdoba and T. Lian, J. Am. Chem. Soc., 2012, 134, 10337-10340.

23 N. L. Reddy, S. Emin, V. D. Kumari and S. Muthukonda Venkatakrishnan, Ind. Eng. Chem. Res., 2018, 57, 568-577.

24 L. Zhu, H. Li, Z. Liu, P. Xia, Y. Xie and D. Xiong, J. Phys. Chem. C, 2018, 122, 9531-9539.

25 L. Yang, H. Li, Y. Yu and H. Yu, Catal. Commun., 2018, 110, 51-54.

26 C.-C. Hu and H. Teng, J. Catal., 2010, 272, 1-8.

27 P. Zhang, T. Wang, X. Chang, L. Zhang and J. Gong, Angew. Chem., Int. Ed., 2016, 55, 5851-5855.

28 H. Shen, D. Ni, P. Niu, Y. Zhou, T. Zhai and Y. Ma, Int. J. Hydrogen Energy, 2017, 42, 30559-30568.

29 B. Çinar, I. Kerimoğlu, B. Tönbül, A. Demírbüken, S. Dursun, I. Cihan Kaya, V. Kalem and H. Akyildiz, Mater. Sci. Semicond. Process., 2020, 109, 104919. 
30 Y. Li and K. Luo, RSC Adv., 2019, 9, 8350-8354.

31 K. Yao, S. Liu, Y.-Y. Dong, B. Wang, J. Bian and M.-G. Ma, Mater. Des., 2016, 90, 129-136.

32 Y. Wang, M. Zhou, Y. He, Z. Zhou and Z. Sun, J. Alloys Compd., 2020, 813, 152184.

33 Z. H. Shah, J. Wang, Y. Ge, C. Wang, W. Mao, S. Zhang and R. Lu, J. Mater. Chem. A, 2015, 3, 3568-3575.

34 G. Yang, H. Ding, J. Feng, Q. Hao, S. Sun, W. Ao and D. Chen, Sci. Rep., 2017, 7, 14594.

35 X. Zhang, L. Wang, C. Liu, Y. Ding, S. Zhang, Y. Zeng, Y. Liu and S. Luo, J. Hazard. Mater., 2016, 313, 244-252.

36 J. Yuan, J.-J. Zhang, M.-P. Yang, W.-J. Meng, H. Wang and J.-X. Lu, Catalysts, 2018, 8, 171.

37 Z. Liu and C. Zhou, Prog. Nat. Sci.: Mater. Int., 2015, 25, 334-341.

38 A. A. Dubale, A. G. Tamirat, H.-M. Chen, T. A. Berhe, C.-J. Pan, W.-N. Su and B.-J. Hwang, J. Mater. Chem. A, 2016, 4, 2205-2216.
39 J. Liu, C. Han, X. Yang, G. Gao, Q. Shi, M. Tong, X. Liang and C. Li, J. Catal., 2016, 333, 162-170.

40 Q. Shi, G. Ping, X. Wang, H. Xu, J. Li, J. Cui, H. Abroshan, H. Ding and G. Li, J. Mater. Chem. A, 2019, 7, 2253-2260.

41 X.-J. Wen, C.-G. Niu, L. Zhang and G.-M. Zeng, ACS Sustainable Chem. Eng., 2017, 5, 5134-5147.

42 W. Wang, Y. Yu, T. An, G. Li, H. Y. Yip, J. C. Yu and P. K. Wong, Environ. Sci. Technol., 2012, 46, 4599-4606.

43 H. Zhuang, Z. Cai, W. Xu, M. Huang and X. Liu, New J. Chem., 2019, 43, 17416-17422.

44 H. Zhuang, Z. Cai, W. Xu, X. Zhang, M. Huang and X. Wang, Catal. Commun., 2019, 120, 51-54.

45 J. Lin, J. Hu, C. Qiu, H. Huang, L. Chen, Y. Xie, Z. Zhang, H. Lin and X. Wang, Catal. Sci. Technol., 2019, 9, 336-346.

46 X. An, Y. Wang, J. Lin, J. Shen, Z. Zhang and X. Wang, Sci. Bull., 2017, 62, 599-601. 